\title{
SOLID DISPERSION OF NEBIVOLOL HYDROCHLORIDE IMPREGNATED BUCCAL PATCH: FORMULATION AND CHARACTERIZATION
}

\author{
CLINTON JOSE ${ }^{1}$, SNEH PRIYA ${ }^{1}$, DIVYA JYOTHI ${ }^{2}$, HIMANSHU JOSHI ${ }^{3}$, CYNTHIA LIZZIE LOBO $^{1}$, KRITHI S. P. ${ }^{1}$ \\ ${ }^{1}$ Nitte (Deemed to be University), NGSM Institute of Pharmaceutical Sciences (NGSMIPS), Department of Pharmaceutics, Derelakatte, \\ Mangaluru, India, ${ }^{2}$ Nitte (Deemed to be university), NGSM Institute of Pharmaceutical Sciences (NGSMIPS), Department of \\ Pharmacognosy, Derelakatte, Mangaluru, India ${ }^{3}$ College of Pharmacy, Graphic Era Hill University, Bhimtal Campus, Utterakhand \\ Email: snehpriya123@nitte.edu.in
}

Received: 21 Jan 2021, Revised and Accepted: 10 Mar 2021

\section{ABSTRACT}

Objective: The objective of the present investigation was to design and characterize a mucoadhesive buccal patch of Nebivolol hydrochloride in order to administer a small dose of a drug to treat hypertension effectively and thereby avoiding disadvantages such as patient noncompliance and low bioavailability.

Methods: The buccal patches were prepared by solvent casting method. The polymers used to formulate patches were HPMC K 15 M, PVP K 30 , and propylene glycol was used as plasticizer and ethanol as the solvent. The drug-polymer compatibility studied was conducted by FTIR.

Results: All the developed Patches had good transparency and stability. All formulated patches showed pH in the range of 6.49 to 7.22 , and drug content was more than $90 \%$. The folding endurance value showed that the patches are flexible and non-brittle. The in vitro residence time was found to more than $30 \mathrm{~min}$. Thickness, \% moisture absorption, and \% moisture loss values were in a normal range. The drug release study was conducted for $8 \mathrm{~h}$, and it was found drug release was decreased with the increase in polymer concentration. The in vitro release profiles of the drug from all the formulations appeared to follow Korsmeyer Peppa's exponential model, and release exponent (n) was found to be more than 0.45 so that the release can be characterized by Non-Fickian (anomalous) diffusion.

Conclusion: From the results, it was concluded that drug released from formulated buccal patches follows sustained release pattern, Hence can be used for the treatment of the hypertensive patient.

Keywords: Nebivolol hydrochloride (NBH), Mucoadhesive buccal patch, HPMC K 15 M

(c) 2021 The Authors. Published by Innovare Academic Sciences Pvt Ltd. This is an open access article under the CC BY license (https://creativecommons.org/licenses/by/4.0/) DOI: https://dx.doi.org/10.22159/ijap.2021v13i3.40851. Journal homepage: https://innovareacademics.in/journals/index.php/ijap

\section{INTRODUCTION}

Hypertension (HTN) or high blood pressure, sometimes called arterial hypertension, is a chronic medical condition in which the arteries' blood pressure is elevated. High blood pressure is present if it is often at or above $140 / 90 \mathrm{~mm} \mathrm{Hg}$. Hypertension is classified as either primary (essential) hypertension or secondary hypertension [1, 2]. The oral route is the most popular and convenient drug administration route. However, oral administration cannot achieve the maximum bioavailability of many drugs because of rapid or extrahepatic firstpass metabolism [3]. Among the different approaches to avoiding the first-pass metabolism, the buccal route seems convenient [4].

Buccal administration refers to a route of administration or topical route of administration. Drugs held or applied in the buccal area (in the cheek) diffuse through the oral mucosa (tissues that line the mouth) and enter directly into the bloodstream. Buccal administration may provide better bioavailability of some drugs and more rapid onset of action than oral administration. The medication does not pass through the digestive system and thereby avoids the first-pass metabolism. Various mucoadhesive devices, including tablets, films, patches, disks, strips, ointments, and gels, have recently been developed. However, buccal patches offer greater flexibility and comfort than other devices. Besides, a patch can circumvent the relatively short residence time of oral gels on mucosa since the gels are easily washed away by saliva. Other advantages such as excellent accessibility, low enzymatic activity, suitability for drugs or excipients that mildly and reversibly damage or irritate the mucosa, painless administration, easy withdrawal, facility to include permeation enhancer/enzyme inhibitor or $\mathrm{pH}$ modifier in the formulation, versatility in designing as multidirectional or unidirectional release system for local or systemic action. There are mainly 3 methods to prepare mucoadhesive buccal patch; they are solvent casting technique, hotmelt extrusion technique, and solvent evaporation method [5].
Polymers frequently used in the buccal delivery system are CMC, HEC, HPC, HPMC, MC, Chitosan, etc.

Nebivolol Hydrochloride (NBH) is a drug with low water solubility and high membrane permeability, as in class 2 in the Biopharmaceutical Drug Classification System. NBH is a beta-blocker that exerts its actions by exhibiting a high selectivity for B-adrenergic receptors and reducing peripheral vascular resistance by modulating nitric oxide release [6]. Nebivolol is indicated as medicine for Essential Hypertension but, it has some drawbacks like extensive first-pass metabolism, gastric irritancy, and low bioavailability. Further, the low aqueous solubility and poor dissolution of this molecule in gastric fluid affect its absorption rate, resulting in a low and variable oral bioavailability. Formulation of poorly water-soluble drugs as solid dispersions leads to increased solubility and decreased gastrointestinal side effects. The resulted of that marked improvement in their dissolution rates and decreased gastrointestinal side effects. An increase often helps it in their relative bioavailability $[7,8]$. So, to improve the solubility, bioavailability and avoid hepatic metabolism, in the present study, an attempt was made to develop solid dispersion loaded buccal patches of Nebivolol [9, 10]. NBH also has a low molecular weight and high partition coefficient, making it a suitable candidate for the buccal delivery system.

\section{MATERIALS AND METHODS}

\section{Materials}

Nebivolol Hydrocholride was a gift sample Cipla Pharma Ltd. (Banglore, India). Hydroxy propylmethyl cellulose (K15 M) was obtained from Yarrow chem products. (Mumbai, India) and Polyvinyl pyrolidone K 30 (PVP K30) was obtained from Central drug house (P) Ltd. (Delhi, India). Ethanol was obtained from Merck specialities Private Limited, (Mumbai, India). Propylene glycol 800 was obtained from Sisco laboratories (Mumbai, India). All other chemicals used were of analytical grade and procured from Hi media laboratories (Mumbai, India). 


\section{Fabrication of nebivolol solid dispersion infused buccal patch}

The buccal patches containing Nebivolol solid dispersions were prepared by incorporating solid dispersions of Nebivolol in a different composition of Hydroxypropyl methylcellulose (HPMC) K15 M polymer. Solid dispersions of Nebivolol were prepared as by Shah I et al., in that 1:7 ratio of drug and PVP K 30 was taken. Different percentages of HPMC K $15 \mathrm{M}$ were taken and dissolved in $20 \mathrm{ml}$ of ethanol. The beakers containing polymer solution were kept aside for $24 \mathrm{~h}$ for swelling of the polymer. Further, $5 \mathrm{ml}$ of ethanol was added to it, and the dispersion was stirred. Then propylene glycol was added to the polymer solution and mixed well.

Accurately weighed amounts of Nebivolol loaded solid dispersion were taken, added slowly in the polymeric solution, and stirred on the magnetic stirrer to obtain a uniform solution. This solution was then made up into $30 \mathrm{ml}$ using ethanol, and then the solution was poured on the Petri dish of diameter $9 \mathrm{~cm}$ and kept for drying. These were left undisturbed at room temperature for one day. After drying, medicated patches of $2 \times 2 \mathrm{~cm} 2$ areas were cut using a sterile stainless steel borer, each film containing $10.0 \mathrm{mg}$ of the drug. The cut patches were used for further studies $[6,11]$. The composition of different formulation showed in table 1.

\section{Drug excipient compatibility studies}

To determine whether there are any interactions between the drug and excipients, FTIR spectroscopic analysis was performed using the instrument BRUKER Alpha II in the region of 2000 to $400 \mathrm{~cm}-1$. All individual components of drug, drug-polymer mixture and patch were analysed.

Table 1: Composition of of each mucoadhesive buccal patch (area $2 \times 2 \mathrm{~cm}^{2}$ )

\begin{tabular}{|c|c|c|c|c|c|c|}
\hline $\begin{array}{l}\text { Formulation } \\
\text { coed }\end{array}$ & $\begin{array}{l}\text { Solid dispersion equivalents to } \\
10 \mathrm{mg} \text { of nebivolol }\end{array}$ & $\begin{array}{l}\text { HPMC K } 15 \\
\text { M (mg) }\end{array}$ & $\begin{array}{l}\text { Propylene } \\
\text { glycol (\%) }\end{array}$ & $\begin{array}{l}\text { Aspartame } \\
\text { (mg) }\end{array}$ & $\begin{array}{l}\text { Peppermint } \\
\text { oil (ml) }\end{array}$ & Ethanol \\
\hline F1 & 80 & 20 & 30 & 0.25 & 0.02 & Q.S. \\
\hline $\mathrm{F} 2$ & 80 & 25 & 30 & 0.25 & 0.02 & Q.S. \\
\hline F3 & 80 & 30 & 30 & 0.25 & 0.02 & Q.S. \\
\hline $\mathrm{F} 4$ & 80 & 35 & 30 & 0.25 & 0.02 & Q.S. \\
\hline F5 & 80 & 25 & 20 & 0.25 & 0.02 & Q.S. \\
\hline F6 & 80 & 25 & 40 & 0.25 & 0.02 & Q.S. \\
\hline
\end{tabular}

\section{Characterization of buccal mucoadhesive patches}

\section{Weight variation}

A weight variation test was carried out using digital balance (Mettler Toledo), by weighing three films containing a specific amount of drug from each formulation. The standard deviations (SD) were calculated from the individual weight of the film [11-13].

\section{Film thickness}

The thickness of the films was determined using a micrometer screw gauge. Thickness of 10 films of each formulation was determined and the average was calculated.

\section{Content uniformity of patches}

To make sure uniform distribution of NBH in film, a content uniformity test was performed. The film was added to $100 \mathrm{ml}$ of sorensons phosphate buffer (SPB) pH 6.4 contained in a $250 \mathrm{ml}$ beaker was placed on a temperature controlled magnetic stirrer maintained at $37^{\circ} \mathrm{C}$. The medium was stirred at $300 \mathrm{rpm}$ with a Teflon coated magnetic bead for $3 \mathrm{~h}$. Then the solution was filtered through $0.45 \mu \mathrm{m}$ membrane filter and the filtrate was examined for the drug content at $281 \mathrm{~nm}$ using UVSpectrophotometer [13].

\section{Surface pH study}

The surface $\mathrm{pH}$ of the patch was determined in order to investigate the possibility of any side effects (in vivo). The patches were allowed to swell by keeping it in contact with $1 \mathrm{ml}$ of distilled water $(\mathrm{pH}$ $6.5 \pm 0.2$ ) for $15 \mathrm{~min}$ at room temperature, and $\mathrm{pH}$ was noted down by bringing the electrode in contact with the surface of the patch and allowing it to equilibrate for 1 minute $[11,13]$.

\section{Percentage moisture absorption}

The percentage moisture absorption test was carried out to ensure physical stability or integrity of buccal films. Buccal films were weighed and placed in a desiccator containing $100 \mathrm{ml}$ of a saturated solution of aluminum chloride and $75 \pm 5 \% \mathrm{RH}$ was maintained. After three days the buccal films were taken out and reweighed. The percentage moisture absorption was calculated using this formula [14].

$$
\% \text { Moisture absorption }=\frac{\text { Final weight }- \text { Initial weight }}{\text { Initial weight }} \times 100
$$

\section{Percentage moisture loss}

To evaluate the integrity of the patches in dry conditions percentage moisture loss test was carried out. The patches were weighed and kept in a desiccator containing anhydrous calcium chloride. After three days, the patches were taken out and reweighed. The formula used to find out the percentage moisture loss is;

$$
\% \text { Moisture loss }=\frac{\text { Initial weight }- \text { Final weight }}{\text { Initial weight }} \times 100
$$

\section{Tensile strength}

Tensile strength was measured using tensile analogy tester (model TKG, FSA, India). Films free from air bubbles or physical imperfections were selected for tensile testing. The two clamps of the tensile tester were adjusted such that the distance between them is $3 \mathrm{~cm}$ by moving the upper clamp. During measurement, the strips were pulled by top clamp at a rate of $100 \mathrm{~mm} / \mathrm{min}$; the force applied was measured until the film was broken. The film samples, which broke at the point of clamping and not between the clamps, were not included in the calculation. Triplicate results for each film were considered. Tensile strength can be computed from the applied load at rupture as a mean of three measurements and cross-sectional area of fractured film using the following equation [15]

$$
\text { Tensile strength }=\frac{\text { Maximum force }}{\text { Area }}
$$

\section{Folding endurance}

A small strip of film was cut evenly and separately folded at the same place until it broke. The number of times the film could be folded at the same place without breaking gives the folding endurance [16].

\section{In vitro residence time}

The in vitro residence time was determined using a locally modified USP disintegration apparatus (Disintegration tester, Electrolab, Mumbai, India). The disintegration medium was composed of 900 $\mathrm{ml}$ of phosphate buffer $\mathrm{pH} 6.4$ maintained at temperature $37 \pm 2{ }^{\circ} \mathrm{C}$. A segment of pig buccal mucosa, $3 \mathrm{~cm}$ long, was glued to the surface of a glass slab, vertically attached to the apparatus. The mucoadhesive film with backing membrane was hydrated from film surface using $15 \mu \mathrm{l}$ phosphate buffer $\mathrm{pH} 6.4$ and then the hydrated surface was brought into contact with the mucosal membrane. The glass slab was vertically fixed to the apparatus and allowed to move up and 
down so that the film was completely immersed in the buffer solution at the lowest point and was out at the highest point. The time necessary for complete erosion or detachment of the film from the mucosal surface was recorded (mean of triplicate determinations) [11].

\section{Drug release study of the buccal patch}

\section{In vitro release study}

The drug release studies were performed with USP dissolution test apparatus (Paddle method). The USP dissolution apparatus was thermo stated at the temperature of $37 \pm 1^{\circ} \mathrm{C}$ and stirred at rate of 50 rpm. Each film was fixed on a glass slide with the help of cyanoacrylate adhesive so that the drug could be release only from upper face. Then the slide has immersed in the vessel containing 500 $\mathrm{ml}$ of $\mathrm{PB} \mathrm{pH} 6.8$ phosphate buffer solution. At predetermined time intervals $3 \mathrm{ml}$ of samples was withdrawn and replaced with fresh medium. After appropriate dilutions with simulated saliva was assayed spectrophotometrically at $281 \mathrm{~nm}$. For drug release three films of each formulation were subjected and the average cumulative percentage drug release was determined [15].

\section{Drug release kinetics}

To study drug release kinetics of buccal patches formulation, data obtained from in vitro release studies were plotted in various kinetic models: zero order (see Equation: 1) as cumulative percentage of drug released versus time, first order (see Equation: 2) as log cumulative percentage of drug remaining versus time [17].

$$
\begin{gathered}
\text { Zero-order equation } Q_{t}=\text { Kot......1 } \\
\text { First order equation } \operatorname{In} Q_{t}=\operatorname{In} Q_{0}+K_{1} t \ldots \ldots .2
\end{gathered}
$$

Where $Q_{t}$ is the percentage of drug release at time $t, K_{0}$ and $K_{t}$ are the coefficients of the equation.

\section{Mechanism of drug release}

Mechanism of drug release from vocal patches was evaluated by subjecting the data obtained from in vitro drug diffusion studies in Higuchi's model (see Equation: 3) as cumulative percentage of drug released versus the square root of time and Korsmeyer-Peppa's model (see equation: 4) as log cumulative percentage drug released versus log time [17].

\author{
Higuchi equation $Q_{t}=\mathrm{Kt}^{1 / 2} \ldots \ldots .3$ \\ Korsmeyer and peppas equation $\mathrm{Q}_{\mathrm{t}}=\mathrm{K}_{\mathrm{p}} \mathrm{t}^{\mathrm{n}} \ldots \ldots . .4$
}

$\mathrm{K}_{\mathrm{p}}$ is constantly incorporating structural and geometrical characteristics of the release device and $n$ is the release exponent indicate the release mechanism.

\section{RESULTS AND DISCUSSION}

Buccal patches loaded with Nebovolol solid dispersion were prepared by solvent casting method. The prepared buccal patches were transparent, smooth, uniform and flexible as shown in fig. 1, except F6, which was tackier and non-uniform.

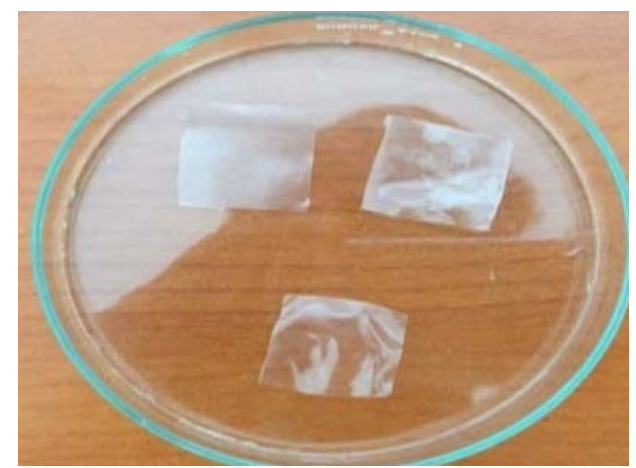

Fig. 1: Buccal patch of nebivolol solid dispersion

\section{IR spectroscopy}

The major IR peaks (wave number, $\mathrm{cm}^{-1}$ ) of pure drug and optimized formulation F3 are given below; Pure NBH: 3397.75, 3187.33, 2903.02, 2845.37, 1749.30,1491.9, 1213.14, 1074.73; Optimized Formulation F3: 3312.97, 3188.78, 2923.41, 2735.69, 1740.33, $1488.83,1209.09,1069.62$. The result showed that the principle IR peak of pure drug and an optimized formulation F3 were almost similar, signifying no interaction between drug and polymer during formation of patch [18].

Table 2: Weight variation, thickness, surface $\mathrm{pH}$ and $\%$ drug content of developed buccal mucoadhesive patch

\begin{tabular}{llll}
\hline Formulation & Weight variation $(\mathbf{m g}) \pm$ SD & Thickness $(\boldsymbol{\mu m}) \pm$ SD & Surface pH \pm SD \\
\hline F1 & $86.63 \pm 0.28$ & $67 \pm 0.94$ & $7.13 \pm 0.09$ \\
F2 & $104.51 \pm 0.19$ & $89 \pm 0.81$ & $6.87 \pm 0.09$ \\
F3 & $109.05 \pm 0.36$ & $97 \pm 0.95$ & $6.64 \pm 0.06$ \\
F4 & $114.71 \pm 0.32$ & $107 \pm 1.63$ & $6.51 \pm 0.11$ \\
F5 & $101.63 \pm 0.21$ & $84 \pm 1.24$ & $9.49 \pm 0.08$ \\
F6 & $103.21 \pm 0.24$ & $88 \pm 0.47$ & $94.20 \pm 0.76$ \\
\hline
\end{tabular}

mean $\pm S D(n=3)$

\section{Weight variation, film thickness, surface $\mathrm{pH}$, and content uniformity of patches}

The results of weight variation, film thickness, surface $\mathrm{pH}$ and content uniformity are represented in table 2. The weights and thickness of different formulations were ranged between $8.63 \pm 0.28$ $\mathrm{mg}$ to $114.71 \pm 0.32 \mathrm{mg}$ and $67 \pm 0.94 \mu \mathrm{m}$ to $107 \pm 1.3 \mu \mathrm{m}$, because of different concentration of polymer and plasticizer. As an acidic or alkaline $\mathrm{pH}$ may cause irritation to the buccal mucosa, an attempt was made to keep the surface $\mathrm{pH}$ as close to neutral as possible. The surface $\mathrm{pH}$ of formulations was found to be in the range of $6.49 \pm 0.08$ to $7.22 \pm 0.06$, which was well within range of neutral $\mathrm{pH}$ and has not cause irritation and ultimately achieves patient compliance. All the formulations exhibited fairly uniform drug content ranging from $88.45 \pm 1.22 \%$ to $95.17 \pm 0.96 \%$, Formulation procedures involving fewer processing steps, no major drug loss was observed during the preparation of the films.

\section{Percentage moisture loss and moisture absorption}

The percentage moisture loss was found to be between $3.48 \pm 0.23$ to $6.63 \pm 0.33$ and percentage moisture absorption was found to be $3.9 \pm 0.10$ to $5.71 \pm 0.33$, as shown in table 3 . The result revealed that the moisture absorption and loss was found to increase with increasing concentration of hydrophilic polymers as well as increase the concentration of hydrophilic plasticizer. The optimum moisture content in the formulations helps the film to remain stable, non-brittle and free from completely drying. Optimum values of moisture absorption in F3 formulation indicate less chance of microbial contamination and maintain integrity through the films shelf life $[19,20]$.

\section{Tensile strength, folding endurance and in vitro residence time}

Tensile strength is defined as the maximum stress applied at a point at which the film specimen breaks. The tensile strength measures the ability of a patch to withstand rupture. As the concentration of 
hydrophilic polymer HPMC K 15 M was increased, there is increase in tensile strength, as shown in table 3.4. Polymers contain large number of chain of molecules and between these chains, homopolar bond and other types of bonds are possible. These bonds are either strong or feeble, depending on the nature of the polymer. According to the bonds formed force required to break the bonds and rupture the patch will differ. The mean value of tensile strength of patch containing different concentrations of HPMC K $15 \mathrm{M}$ was found to vary between $4.11 \pm 1.51$ to $8.55 \pm 0.98 \mathrm{~kg} / \mathrm{mm} 2$ (F1 to F4). As the concentration of plasticizer propylene glycol was increased (20 to $40 \%$ ) there is an increase in tensile strength (Patel and Poddar 2009, as shown in formulation F4, F3 and F5. The mean value of tensile strength of patch containing different concentration of plasticizer was found to be $4.33 \pm 1.27,7.72 \pm 0.40$ and $8.28 \pm 0.65$ $\mathrm{kg} / \mathrm{mm}^{2}$ for formulation F4, F3 and F6, respectively. Presence of a plasticizer in the formulation helps in imparting strength to the films by lubrication effect of the plasticizer and reduction of the cohesive force between chain molecules of polymer. As a result, tensile strength of the films will be reduced. The formulation F3 showed optimum tensile strength which indicates less probability of rupture. The values for folding endurance varied from $32 \pm 3.87$ to $158 \pm 4.37$, as shown in [table 3]. The value depends on hydrophilic polymer as well as plasticizer concentrations used. Folding endurance test results indicated that the patches would not break and would maintain their integrity with general skin folding when applied. In vitro residence time studies showed that all patches adhered immediately to the buccal mucosa and showed residence times above $30 \mathrm{~min}$. HPMC K $15 \mathrm{M}$ is a non-ionic polymer having unique gelling characteristics, which in turn are responsible for its adhesive properties. It exhibits strong bioadhesive behavior either because of hydrogen bonding due to hydroxyl groups or because of significant chain penetration or both (Thakur and Ratnaparkhi, 2014).

Table 3: Tensile strength, folding endurance, \% moisture absorption and Moisture loss of developed formulations of betamethasone sodium phosphate

\begin{tabular}{|c|c|c|c|c|c|}
\hline Formulation & $\begin{array}{l}\text { Percentage moisture } \\
\text { absorption } \pm \text { SD }\end{array}$ & $\begin{array}{l}\text { Percentage } \\
\text { moisture loss } \pm \text { SD }\end{array}$ & $\begin{array}{l}\text { Folding } \\
\text { endurance } \pm S D\end{array}$ & $\begin{array}{l}\text { Tensile strength } \\
\mathrm{Kg} / \mathrm{cm}^{2} \pm \mathrm{SD}\end{array}$ & $\begin{array}{l}\text { In vitro residence } \\
\text { time }\end{array}$ \\
\hline F1 & $3.90 \pm 0.19$ & $3.48 \pm 0.23$ & $32 \pm 3.87$ & $4.11 \pm 1.51$ & $>30$ \\
\hline $\mathrm{F} 2$ & $4.09 \pm 0.32$ & $5.73 \pm 0.39$ & $59 \pm 2.83$ & $5.34 \pm 0.95$ & $>30$ \\
\hline F3 & $5.50 \pm 0.21$ & $5.81 \pm 0.50$ & $93 \pm 3.58$ & $7.72 \pm 0.40$ & $>30$ \\
\hline F4 & $5.71 \pm 0.33$ & $6.63 \pm 0.33$ & $158 \pm 4.37$ & $8.55 \pm 0.98$ & $>30$ \\
\hline F5 & $4.45 \pm 0.53$ & $4.20 \pm 0.31$ & $76 \pm 2.01$ & $4.33 \pm 1.27$ & $>30$ \\
\hline F6 & $5.23 \pm 0.43$ & $5.33 \pm 0.42$ & $135 \pm 4.02$ & $5.28 \pm 0.65$ & $>30$ \\
\hline
\end{tabular}

mean $\pm S D(n=3)$

\section{In vitro drug release studies}

In vitro release of all formulation were performed and results are shown in fig. 2 and 3. The maximum percentage of drug released from the formulations F1 to F4 was found to be $95.88 \pm 3.03$, $92.29 \pm 2.72,90.18 \pm 2.59$, and $75.88 \pm 2.43$ at the end of $480 \mathrm{~min}$. It was found that increase in the concentration of polymer significantly decreased the drug release. The slow drug release mechanism for higher polymer concentration can be explained by the reduction in permeability due to change in the morphology of the polymer. Improved polymer concentration may have providing the matrix with greater tortuosity and deprived water porosity for diffusion of drug [20,21]. In vitro release of drug also depends on nature of plasticizer. As the concentration of hydrophilic plasticizer was increased, the release of drug was also found to be increased, asshown in fig. 2. It may be due to quick absorption of water by formation of large number of hydrogen bonds and helped in faster diffusion of drug from the system. Formulation F5, F3 and F6 were contained different concentrations of plasticizer i.e. 20, 30 and $40 \%$ respectively and maximum drug release at the end of 480 min was found to be $62.15 \pm 2.39,90.18 \pm 2.59$ and $93.18 \pm 1.19$ respectively.

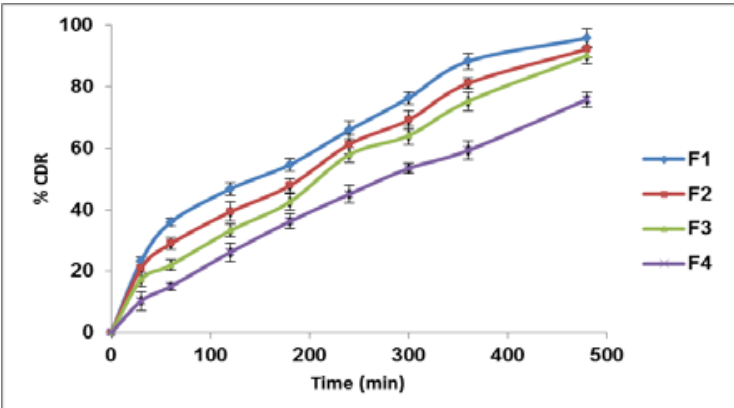

Fig. 2: In vitro release studies of buccal patches of nebivolol contains a different concentration of HPMC K15 M[mean \pm SD $(n=3)]$

\section{Drug release kinetics}

For the investigation of drug release kinetics, release data were fitted to various kinetic models and results shown in table 4 . In vitro drug release was best fitted to zero order as the plot indicates highest linearity regression coefficient $\left(\mathrm{R}^{2}\right)$ when compared to first-order kinetic model. The mechanism of drug release from buccal patches was studied by fitting the data into Higuchi model and korsmeyer peppa's exponential model. The corresponding in vitro release plot of Korsmeyer-peppa's equation indicated good linearity of regression coefficients (Patel and Poddar 2009). Release exponent (n) was found to be more above 0.45 , so that the release can be characterized by non-fickian (anomalous) diffusion, which may indicate that the drug release rate is controlled by more than one mechanism i.e. Diffusion coupled with erosion mechanism [22, 23].

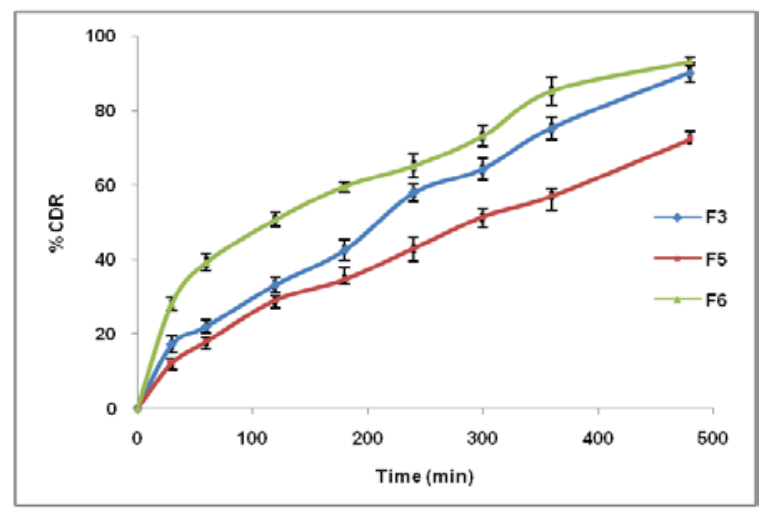

Fig. 3: In vitro release studies of buccal patches of nebivolol contains different concentration of propylene glycol [mean \pm SD $(n=3)]$

Based on physicochemical properties, in vitro residence time and in vitro drug release studies, formulation F3 was found to be optimized. Tensile strength of formulation F3 was sufficient to maintain the integrity of the film and it showed adequate residence time to keep the film at the site of administration. From in vitro drug release study, it was found that F3 showed maximum release $(90.18 \pm 2.59)$ at the end of $30 \mathrm{~min}$ which was the prerequisite for the achievement of therapeutic action. However, formulations F1 and F2 containing lower concentration of HPMC K 15 M showed more 
release compared to $\mathrm{F} 3$ at the end of $480 \mathrm{~min}$, but tensile strength was lesser than F3. But formulations F4 containing high concentration of HPMC K 15 M showed less release and high tensile strength compare to F3. Formulation F6 also showed more drug release compared to F3, since it content higher amount of plasticizer, but it was rejected because of its sticky nature.

Table 4: Kinetic parameter for in vitro drug release from buccal patches of nebivolol

\begin{tabular}{|c|c|c|c|c|c|c|c|}
\hline Kinetic model & & F1 & F2 & F3 & F4 & F5 & F6 \\
\hline \multirow[t]{2}{*}{ Zero Order } & $\mathrm{R}^{2}$ & 0.9701 & 0.987 & 0.9917 & 0.9932 & 0.9939 & 0.9683 \\
\hline & $\mathrm{K}$ & -0.161 & -0.162 & -0.167 & -0.145 & -0.13 & -0.14 \\
\hline \multirow[t]{2}{*}{ First Order } & $\mathrm{R}^{2}$ & 0.941 & 0.9495 & 0.9444 & 0.9806 & 0.9826 & 0.955 \\
\hline & $\mathrm{K}$ & -0.0027 & -0.0021 & -0.002 & -0.0012 & -0.0011 & -0.0022 \\
\hline \multirow[t]{2}{*}{ Higuchi } & $\mathrm{R}^{2}$ & 0.9886 & 0.986 & 0.9806 & 0.9885 & 0.9862 & 0.9917 \\
\hline & $\mathrm{K}$ & 4.488 & 4.45 & 4.5654 & 3.9959 & 3.5718 & 3.924 \\
\hline \multirow{3}{*}{$\begin{array}{l}\text { Korsmeyer Peppas } \\
\text { model }\end{array}$} & $\mathrm{R}^{2}$ & 0.9911 & 0.9889 & 0.9831 & 0.9972 & 0.9966 & 0.9938 \\
\hline & $\mathrm{K}$ & 0.5059 & 0.5434 & 0.6208 & 0.7361 & 0.6341 & 0.4238 \\
\hline & $\mathrm{n}$ & 0.6267 & 0.49 & 0.2688 & 0.102 & 0.1362 & 0.8256 \\
\hline
\end{tabular}

\section{CONCLUSION}

The buccal patches are very comfortable due to nonirritating to tissue and can be easly apply and revome. The buccal patches of Nebivolol required lower doage compared to conventional tablets and able to deliver a drug over $6 \mathrm{hr}$ continuously. Results illustrate the drug release was decreases with polymer and increases plastsizer.

\section{ACKNOWLEDGEMENT}

The authors are thanks to authorities of Nitte (Deemed to be University) and NGSM Institute of Pharmaceutical Sciences for providing the financial support and facilities for performing the project. Authors are thankful to Cipla Ltd., banglore, India for providing us with the gift sample of Nebivolol hydrochloride.

\section{FUNDING}

Nil

\section{AUTHORS CONTRIBUTIONS}

All authors have contributed equally.

\section{CONFLICT OF INTERESTS}

Declared none

\section{REFERENCES}

1. Weber MA, Schiffrin EL, White WB, Mann S, Lindholm LH, Kenerson JG, et al. Clinical practice guidelines for the management of hypertension in the community: a statement by the American society of hypertension and the international society of hypertension. J Hypertens 2014;32:3-15.

2. Kearney PM, Whelton M, Reynolds K, Whelton PK, He J. Worldwide prevalence of hypertension: a systematic review. J hypertens 2004;22:11-9.

3. Gavhane YN, Yadav AV. Loss of orally administered drugs in GI tract. Saudi Pharm J 2012;20:331-44.

4. Harris D, Robinson JR. Drug delivery via the mucous membrane of the oral cavity. J Pharm Sci 1992;81:1-10.

5. Tarun P, Kumar V, Kumar A. Drug delivery via the buccal patcha novel approach. Indo Am J Pharm Res 2013;3:3466-83.

6. Veverka A, Nuzum DS, Jolly JL. Nebivolol: a third-generation $\beta$ adrenergic blocker. Ann Pharmacother 2006;40:1353-60.

7. Shah I, Bhatt S, Yadav A. Enhancement of solubility and dissolution of nebivolol by solid dispersion technique. Int J Pharm Pharm Sci 2014;6:566-71.

8. Shah H, Shah V, Bhutani S, Parikh D, Mehta T. Dissolution improvement of nebivolol hydrochloride using solid dispersion adsorbate technique. Asian J Pharm 2015;9:49-55.
9. Hirlekar RS. Design of buccal drug delivery system for a poorly soluble drug. Asian J Pharm Clin Res 2009;2:49-53.

10. Periolia L, Ambrogia V, Angelicia F, Riccia M, Giovagnolia S, Capuccellab M, Rossi C. Development of mucoadhesive patches for buccal administration of ibuprofen. J Controlled Release 2004;9:73-82.

11. Priya S, Rathnanand M, Udupa N, Ongole R, Sumanth KN, Joshi U. Preparation and evaluation of buccal mucoadhesive patch of betamethasone sodium phosphate for the treatment of oral submucous fibrosis. J Chem Pharm Res 2011;3:56-65.

12. Patel VM, Prajapati BG, Patel MM. Design and in vitro characterization of eudragit containing mucoadhesive buccal patches. Int J Pharm Tech Res 2009;1:783-9.

13. Averineni RK, Sunderajan SG, Mutalik S, Nayak U, Shavi G, Armugam K, et al. Development of mucoadhesive buccal films for the treatment of oral sub-mucous fibrosis: a preliminary study. Pharm Dev Technol 2009;14:199-207.

14. Deshpande PB, Dandagi P, Udupa N, Shavi VG, Jain SS, Vasanth SG. Controlled release polymeric ocular delivery of acyclovir. Pharm Dev Technol 2009;15:369-78.

15. Thakur P, Ratnaparkhi MP. Formulation and evaluation of mouth dissolving film of felodipine. Res J Pharm Technol 2014;7:1145-9.

16. Wani MS, Dehghan MH, Mahendrakumar C, Polshettiwar SA, Yadav VB. Design and evaluation of terbutaline sulphate buccal patch. Res J Pharm Technol 2009;2:86-90.

17. Singhvi G, Singh M. Review: in vitro drug release charecterization models. Int J Pharm Sci Res 2011;2:77-84.

18. Moffat AC, Osselton MD, Brain W. Clarke's analysis of drugs and poisons overview. $3^{\text {rd }}$ Edition. Pharmaceutical Press: Londom; 2009.

19. Gupta JRD, Irchhiaya R, Garud N, Tripathi P, Dubey P, Patel JR. Formulation and evaluation of matrix type transdermal patches of glibenclamide. Int J Pharm Sci Drug Res 2009;1:4650 .

20. Gawai N, Zaheer Z. Formulation and development of mucoadhesive sustained release buccal tablets and patches of 5-fluorouracil using different polymers. Asian J Pharm Clin Res 2018;11:174-85.

21. Patel RS, Poddar SS. Development and characterization of mucoadhesive buccal patches of salbutamol sulphate. Curr Drug Delivery 2009;6:140-4.

22. Ashutosh R, Prabhakara P, Akhilesh D. Design and evaluation of buccal patches containing combination of hydrochlorothiazide and atenolol. Int J Appl Pharm 2018;10:105-12.

23. Soji S, Arun JL. Development, evaluation, and characterization of Losartan potassium buccal patches using jackfruit polymer. Asian J Pharm Clin Res 2019;12:24-30. 